\title{
Murine Mast Cells Synthesize Basement Membrane Components A Potential Role in Early Fibrosis
}

\author{
Helen L. Thompson, Peter D. Burbelo,* Gary Gabriel,“ Yoshihiko Yamada, * and Dean D. Metcalfe \\ Mast Cell Physiology Section, Laboratory of Clinical Investigation, National Institute of Allergy and Infectious Diseases; \\ and ${ }^{*}$ Laboratory of Developmental Biology and Anomalies, National Institute of Dental Research, \\ National Institutes of Health, Bethesda, Maryland 20892
}

\begin{abstract}
Mast cells are resident in tissues, particularly in association with endothelial and epithelial cell basement membranes, and increase at sites of inflammation, injury, and fibrosis. Although mast cells are known to both release and generate proinflammatory molecules in response to inflammatory stimuli, little is known about their normal biologic function. Here we demonstrate that IL-3-dependent mouse PT18 mast cells, mouse bone marrow-derived mast cells, and rat basophilic leukemia cells express large amounts of mRNA for collagen IV, laminin, and heparan sulfate proteoglycan. Western blot analysis confirmed that mast cells synthesize and secrete significant amounts collagen IV and laminin B1 and B2 chains. These data suggest that mast cells may contribute to normal tissue repair and/or the early overproduction of basement membrane components seen in a variety of fibrotic conditions. (J. Clin. Invest. 1991.87:619-623.) Key words: mast cell • basement membrane - fibrosis • wound healing
\end{abstract}

\section{Introduction}

Fibrosis is characterized by an increase in fibrous components of extracellular matrix. The cells responsible for early changes in the fibrotic cascade are unknown and little is known about the role of inflammatory cells in the fibrotic process (1). The present dogma suggests that the accumulation of inflammatory cells results in the release of a variety of cytokines that can influence fibroblast and endothelial cell function. Thus several days after injury, fibroblasts accumulate that synthesize large amounts of collagen I and collagen II (2). However, little is known about which cells contribute to the early increased basement membrane collagen IV production seen in fibrotic disorders (3).

Mast cells are involved in many types of inflammation and repair processes and are found in increased numbers in fibrotic tissues in skin, intestine, and lung. For example, increased mast cell numbers have been documented in the lesional skin of early scleroderma patients (4), while bleomycin-induced experimental lung fibrosis in rats results in a dramatic increase in mast cell number (5). In systemic mastocytosis, a disease characterized by increased mast cell numbers in the skin, bone marrow, spleen, liver, and lymph nodes, significant fibrotic

Address correspondence to Dr. Helen L. Thompson, Mast Cell Physiology, NIH, NIAID, Bldg. 10, Room 11C208, 9000 Rockville Pike, Bethesda, MD 20892

Received for publication 14 February 1990 and in revised form 9 July 1990.

The Journal of Clinical Investigation, Inc.

Volume 87, February 1991, 619-623 tissue is evident in the bone marrow and liver (6). In many of these diseases, ultrastructural analysis has indicated the slow release of granule contents conveying the impression of mast cell disappearance, and which is quickly followed by mast cell and fibroblast hyperplasia (7). Although mast cells are known to variously synthesize granule-associated heparin and/or chondroitin sulfate proteoglycans (8), little is known concerning the synthesis of extracellular matrix components by these cells. Because of this, and the known association of mast cells with basement membrane and with fibrosis, we have examined the possibility that mast cells may synthesize certain components of extracellular matrix.

\section{Methods}

Materials. The following were purchased: RPMI 1640, EMEM, Hepes (Biofluids Inc., Rockville, MD), penicillin/streptomycin, nonessential amino acids, L-glutamine, sodium pyruvate (Flow Laboratories Inc., McLean, VA) and FCS (HyClone Laboratories, Logan, UT).

Cell cultures. The PT 18 cell line was grown in RPMI 1640 supplemented with $25 \mathrm{mM}$ Hepes, $4 \mathrm{mM}$ L-glutamine, $100 \mu \mathrm{g} / \mathrm{ml}$ penicillin/ streptomycin, $0.1 \mathrm{mM}$ nonessential amino acids, and $1 \mathrm{mM}$ sodium pyruvate (complete RPMI), $10 \%$ vol/vol FCS and $10 \% \mathrm{vol} / \mathrm{vol}$ WEHI3-conditioned media obtained as described (9). Mouse bone marrow mast cells were obtained from primary bone marrow cultured for $3 \mathbf{w k}$ in complete RPMI supplemented with $10 \% \mathrm{vol} / \mathrm{vol} \mathrm{FCS} \mathrm{and} 20 \mathrm{U} / \mathrm{ml}$ of purified IL-3 (10). Rat basophilic leukemia (RBL) ${ }^{1}$ cells were maintained in EMEM supplemented with 15\% FCS as described (11).

Northern blot analysis. Total RNA was extracted from mast cells by the guanidine isothiocyanate procedure of Chirgwin et al. (12) and $5 \mu \mathrm{g}$ of total RNA was separated on $1 \%$ formaldehyde agarose gel (13) and transferred to nitrocellulose. The cDNA probes used were a Pst fragment of the $\mathrm{COOH}$ terminus of the $\alpha$ (IV) collagen chain comprising nucleotides 145-981 (14), a 1.4-kb EcoRI laminin A chain cDNA, comprising nucleotides 5232-6640 (15), a 300-bp HindIII-EcoRI fragment of the mouse laminin B1 chain nucleotides 566-1698 (16), and a 2.5-kb EcoRI-Accl fragment of the mouse laminin B2 chain made up of nucleotides 4409-6120 (17), 666 of which are translated, a 1986-bp fragment of the heparan sulfate proteoglycan with an open reading frame of 662 containing two cysteine rich regions with homology to the cystein rich regions of laminin and two internally homologous domains lacking cysteine (18) and a 1,600-bp PvuIIBamHI fragment including the collagen helix of the rat $\alpha 1(\mathrm{I})$ chain (19). Each CDNA was labeled by the random prime method and used as probe. Hybridization was performed at $42^{\circ} \mathrm{C}$ and the filters were washed at $42^{\circ} \mathrm{C}$ for $1 \mathrm{~h}$ in $0.1 \%$ SSC (sodium chloride $3 \mathrm{M}$, sodium citrate $0.3 \mathrm{M}$; Biofluids Inc., Rockville, MD), $0.1 \%$ SDS, followed by $1 \mathrm{~h}$ at room temperature.

Western blot analysis. Western blot analysis was performed as described (20). Briefly, cells were cultured in the presence of $50 \mu \mathrm{g} / \mathrm{ml}$ of $\beta$-aminopropionitrile. Cell pellets from $\sim 8 \times 10^{6}$ PT 18 cells, RBL cells, or mouse bone marrow mast cells were dissolved in $2 \times$ sample buffer containing $0.125 \mathrm{M}$ Tris- $\mathrm{HCl}, \mathrm{pH} 6.8,10 \%$ glycerol, $4 \%$ SDS,

1. Abbreviation used in this paper: RBL, rat basophilic leukemia. 
and $0.05 \mathrm{mg} / \mathrm{ml}$ bromophenol blue. $40 \mu \mathrm{g}$ of total protein, as determined by a Lowry protein assay, and corresponding to $\sim 5 \times 10^{6}$ cells, were boiled and electrophoresed on a 5\% SDS-PAGE gel including a separate lane for molecular weight standards. Cell supernatants from cells maintained at a concentration of $10^{6}$ cells $/ \mathrm{ml}$ for $24 \mathrm{~h}$ were treated similarly. Protein was transferred from the gel to nylon membrane (Immobilon; Millipore, Bedford, MA), and the molecular weight standard lane was removed and stained with amido black. Nonspecific sites on the remainder of the filter were blocked with $50 \mathrm{mM}$ Tris- $\mathrm{HCl}, \mathrm{pH}$ 7.5 , containing $150 \mathrm{mM} \mathrm{NaCl}, 0.2 \% \mathrm{NP}-40$, and 3\% BSA. The blot was then incubated with either rabbit antisera against collagen IV or laminin, or goat antisera against collagen I. After $2 \mathrm{~h}$, the blot was washed with the same buffer. Horseradish peroxidase-conjugated anti-rabbit or anti-goat antibody was incubated in the same buffer for a further 90 min. After extensive washing, color detection was performed using 4chloronapthol (Sigma Chemical Co., St. Louis, MO) as substrate.

\section{Results}

Specific transcripts for the basement membrane components in murine mast cells. Initial studies were undertaken using the murine IL-3-dependent PT 18 mast cell line, which possesses many of the characteristics of mucosal mast cells in terms of histamine content and proteoglycan synthesis $(21,22)$. Total RNA isolated from PT 18 cells was hybridized with the murine cDNA probes specific for the collagen $\alpha 1$ (IV) chain (14); and the laminin A, B1, and B2 chains (15-17); the core protein of the basement membrane heparan sulfate proteoglycan (18); and the rat collagen $\alpha \mathrm{l}(\mathrm{I})$ chain (19). The Northern blot analysis revealed mRNA species for the laminin B1 chain of $6.0 \mathrm{~kb}$ (Fig. 1, lane 3), laminin B2 chain of $7.5 \mathrm{~kb}$ (lane 4), $\alpha$ (IV) of $6.8 \mathrm{~kb}$ (lane 5), laminin A chain of $10 \mathrm{~kb}$ (lane 6), and heparan sulfate proteoglycan of $12.0 \mathrm{~kb}$ (lane 7 ), consistent with the size of these components. In contrast, even after four times the exposure length of the autoradiograph as compared with the autoradiographs for the other Northern analyses, specific transcripts for the $\alpha 1$ (I) collagen chain of $5.0 \mathrm{~kb}$ were not detected in Northern blot analysis with the cDNA probe for collagen I (Fig. 1, lane 2); however, under this length of exposure some nonspecific hybridization of the probe to the 28 and 18S RNA was apparent. As an indication of the relative amounts of each mRNA expressed by the cells, the filter was rehybridized with a $\beta$-actin cDNA probe (Fig. 1, lane 1 ), which in most cell types including mast cells, will give a strong signal.
To confirm whether mast cells derived from primary cell cultures also expressed mRNA for basement membrane components, total RNA was isolated from mouse bone marrow cells cultured in the presence of IL-3 for $3 \mathrm{wk}$. These cultures are composed of $\sim 90 \%$ mast cells and can be further purified to $>99 \%$ by the adsorption of macrophages to the tissue culture flask. Northern blot analysis of total RNA isolated from bone marrow-derived mast cells also revealed transcripts for the components of basement membrane, the $\alpha$ (IV) chain of collagen (Fig. 2, lane 2), the B1 and B2 chains of laminin (Fig. 2 , lanes 3 and 4, respectively), the laminin A chain (lane 5), heparan sulfate proteoglycan (lane 6 ), and $\beta$-actin (lane 1 ). Specific transcripts for the $\alpha 1$ (I) chain were not detected (data not shown).

Finally, using these cDNA probes we examined the extracellular matrix components synthesized by the RBL line. Again, high levels of expression of transcripts for $\alpha 1$ (I) collagen IV chain (Fig. 3, lane 4), the laminin A chain (lane 5), heparan sulfate proteoglycan (lane 6 ), and $\beta$-actin (lane 1 ) were observed, while lower levels of mRNA for the laminin B1 and B2 chains were detected (Fig. 3, lanes 2 and 3, respectively). Again mRNA for the collagen $\alpha 1(\mathrm{I})$ chain was not detected in RBL cells (data not shown).

Synthesis and secretion of basement membrane components in murine mast cells. To establish whether PT18 mast cells, mouse bone marrow mast cells, and RBL cells translate these mRNA and secrete the protein, the cells were cultured for $24 \mathrm{~h}$ in the presence of $\beta$-aminopropionitrile in order to prevent collagen crosslinking. The cells and media were collected, electrophoresed, and immunoblotted with various antibodies to basement membrane components. Western blot analysis of both the cells and cell media from these cell cultures, with antibody to collagen IV (23), revealed that mast cells synthesize and secrete both the $\alpha$ I(IV) and $\alpha 2$ (IV) collagen chains showing the characteristic doublet at $\sim 180 \mathrm{kD}$ (Fig. 4). Western blot analysis with a polyclonal antibody against murine laminin (24) indicated that mast cells from primary bone marrow cultures and the RBL and PT 18 cell lines synthesize significant amounts of the B1 and B2 chains of laminin at $\sim 220 \mathrm{kD}$, while little A chain could be detected (Fig. 5).

To validate the absence of the collagen $\alpha 1$ (I) chain as determined by Northern analyses, Western blot analysis of collagen I production was also performed for RBL cells, PT 18 cells, and

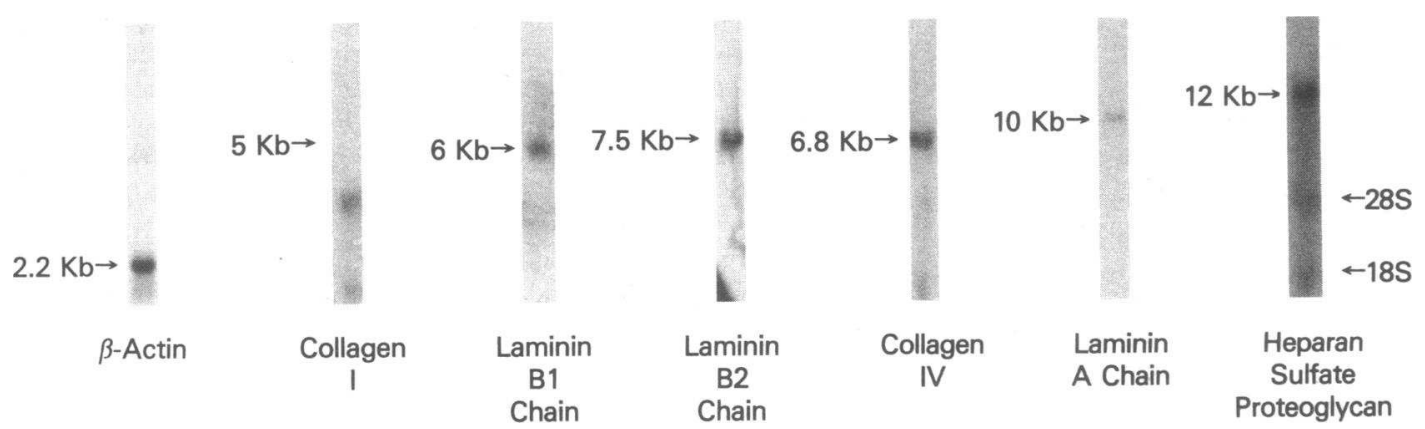

Figure 1. IL-3-dependent PT18 mast cells express mRNAs for basement membrane components. Northern analysis of total RNA from IL-3dependent PT 18 mast cells. Total RNA was probed with the cDNA probes for $\beta$-actin (lane 1), $\alpha 1$ (I) collagen chain (lane 2), laminin B1 chain (lane 3), laminin B2 chain (lane 4), $\alpha$ (IV) collagen chain (lane 5), laminin A chain (lane 6), and basement membrane heparan sulfate proteoglycan (lane 7). The size of the corresponding mRNA species is indicated on the left side of each lane and 28S and 18S ribosomal RNA are shown on the right. Results shown are representative of four experiments. 


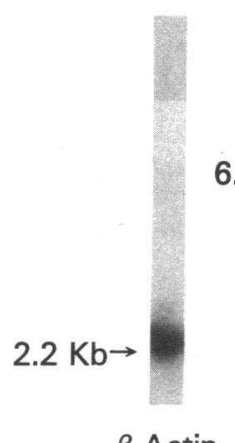

$\beta$-Actin

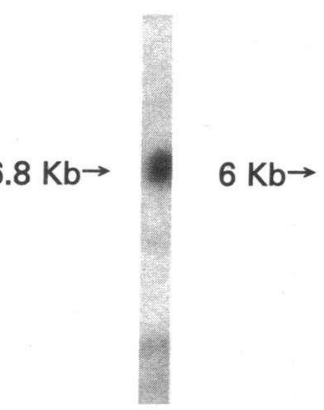

Collagen

IV

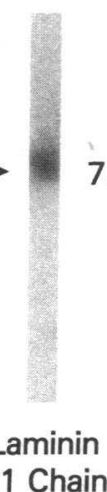

B1 Chain

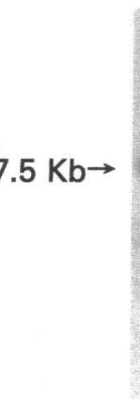

Laminin B2 Chain
10

$10 \mathrm{~Kb}$

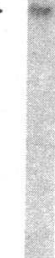

Laminin

A Chain
Figure 2. Mouse bone marrowderived mast cells express mRNAs for basement membrane components. Northern analysis of total RNA from mouse bone marrowderived mast cells. Nytran filters were hybridized with the cDNA probes for $\beta$-actin (lane I), $\alpha$ 1(IV) collagen chain (lane 2), laminin B1 chain (lane 3), laminin B2 chain (lane 4), laminin A chain (lane 5), and heparan sulfate proteoglycan (lane 6). Sizes of detected RNA species are indicated on the left of each lane. Results shown are representative of four experiments. mouse bone marrow mast cells. Immunoblotting of cell protein and cell supernatants with a goat anti-collagen I antibody did not identify the presence of collagen $\alpha 1$ (I) chains in any of the cell preparations (data not shown).

\section{Discussion}

In the present study we have presented data to support the conclusion that mast cells are capable of synthesizing the components of basement membrane. The observation that mast cells synthesize the components of the basement membrane and not the other components of the extracellular matrix, such as collagen I, was unexpected. Macrophages have been shown to synthesize small amounts of laminin (25), but little is known about the synthesis of collagen by these cells. It appears that most inflammatory cells do not synthesize collagen I or collagen IV, and hence mast cells would appear unique in this regard. The inability to detect the A chain of laminin may be a consequence of the fact that the three chains of laminin are not expressed equally in mast cells. Additionally, as in the case of the PT1 8 cells, the laminin A chain mRNA may be poorly translated. Since the laminin A chain appears to contain an active site for mast cell attachment (Thompson, H. L., unpublished observations), and is required in conjunction with the laminin B1 and B2 chains for the proper assembly and deposi- tion of the laminin molecule, the lack of detectable laminin A chain may explain why PT 18 cells and mouse bone marrow mast cells do not attach to their own matrix. The nature of RBL cell adherence to plastic surfaces is not clear, but upon the basis of the present results it would not appear to be a result of adherence to laminin matrix. The selective synthesis of one or more of the chains of laminin has been observed in a number of other cell types $(26,27)$, where the synthesis of the A chain of laminin follows at a later stage of differentiation (27).

The established mast cell lines and the primary mast cell culture examined in this report possess some of the characteristics of mucosal mast cells. In vivo, however, it is the connective tissue mast cell that appears most often to be associated with regions where fibrosis is established (5). Type I and III collagens are found at such sites. There is, however, little information on the characteristics of mast cells that appear either before or as fibrosis first develops and in sites of collagen IV production. It is possible, for example, that the phantom mast cells observed in early scleroderma may be mucosal mast cells or mucosallike mast cell precursors. Alternatively, connective tissue mast cells may be also capable of synthesizing components of the basement membrane. Studies are under way to explore this possibility. It should be noted, however, that the presence of mucosal and connective tissue mast cells is not necessarily accompanied by fibrosis indicating the probability that mast cells associated with fibrosis may be themselves unique or may have

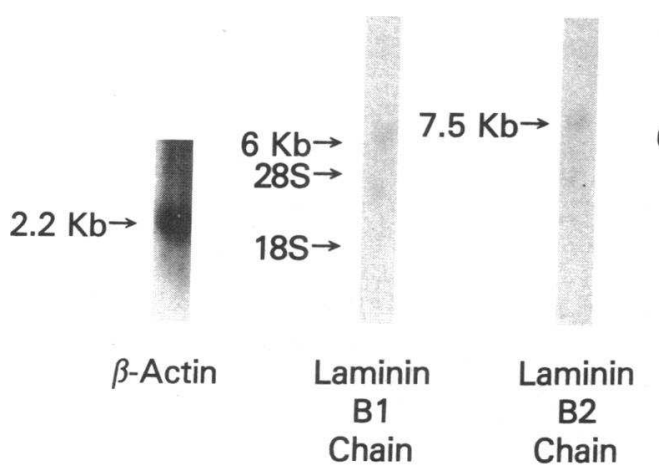

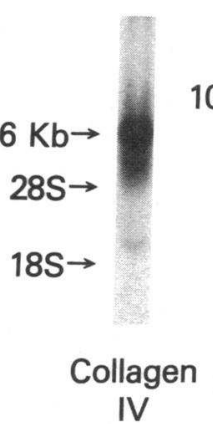

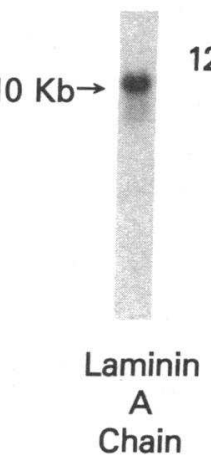

Figure 3. RBL cells express mRNAs for basement membrane components. Northern analysis of total RNA from RBL cells. Total RNA was probed with the cDNA probes for $\beta$-actin (lane 1 ), laminin B1 chain (lane 2), laminin B2 chain (lane 3 ), $\alpha$ l(IV) collagen chain (lane 4), laminin A chain (lane 5 ), and heparan sulfate proteoglycan (lane 6). Sizes of detected RNA species are indicated on the left of each lane. Results shown are representative of three experiments. 


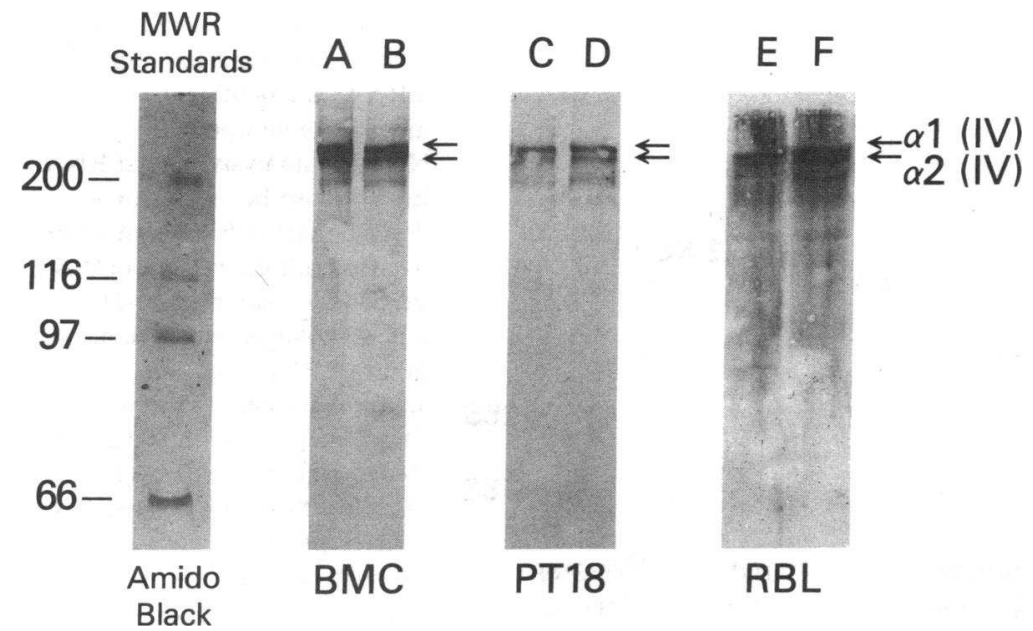

Figure 4. Mast cells synthesize collagen IV. Immunoblotting of protein from cell pellets $(A, C$, and $E)$ and cell supernatants $(B, D$, and $F)$ from mouse bone marrow-derived mast cells $(A, B)$, PT 18 cells $(C, D)$, and RBL cells $(E, F)$, with antisera to murine collagen IV. Molecular weight standards stained with amido black are shown on the left hand side. Results shown are representative of five experiments. been stimulated to produce connective tissue components by specific stimuli unique to the fibrosis process. In some cases, where there is an documented overaccumulation of mast cells, such inappropriate stimuli may result in the overproduction of collagen IV or laminin leading to the early sequence of events seen in fibrosis. For example, both human and experimental liver fibrosis $(28,29)$ show peri-sinusoidal localization of laminin where it is not normally found, although the cells responsible for this have not been identified. In pulmonary fibrosis increased collagen IV, in addition to interstitial collagens, has been observed (30). Thus, the overproduction of the basement membrane components by mast cells may enhance fibroblast attachment, spreading, and proliferation (31) and also mediate a substantial, independent fibrotic element of its own.

The production of basement membrane components by mast cells and under specific circumstances may have a role in the normal function of these cells. First, there is a well-documented association between mast cells, basement membrane, endothelial cells, and epithelial cells. It is possible that the close proximity of mast cells to basement membrane allows mast cells in areas of injury, to contribute to the formation of basement membrane and that through this mechanism mast cells may influence the outgrowth of endothelial cells in capillary formation. Second, the synthesis of basement membrane com- ponents may be important for the growth and differentiation of nearby cells. Basement membrane components have been shown to be effective in the presentation of growth factors to cells (32), some of which mast cells may produce after degranulation $(33,34)$. For example, mast cells may produce the granulocyte/macrophage colony-stimulating factor, which has been shown to be chemotactic for endothelial cells (35), thus allowing new capillary formation in injured tissues. Third, mast cells have been shown to attach and spread on a laminin substratum, although not on collagen I or collagen IV (36) and this matrix would appear to alter mast cell gene expression (37). Hence, the synthesis of laminin receptors in addition to laminin protein by mast cells may be linked to the constitutive expression of a number of different gene products contributing to the growth and differentiation of mast cells in proximity to the basement membrane. In addition, the acquisition of laminin receptors occurs at an early stage of differentiation. We have recently shown that mast cell precursors bearing high affinity IgE receptors derived from mouse bone marrow cultured for $1 \mathrm{wk}$ in the presence of IL-3 possess functional laminin receptors. This would then allow mast cell precursors to migrate to areas of existing basement membrane, complete their process of differentiation, and pursue their role in the synthesis of basement membrane. Fourth, the production of laminin by laminin receptor-bearing cells would provide a mechanism by

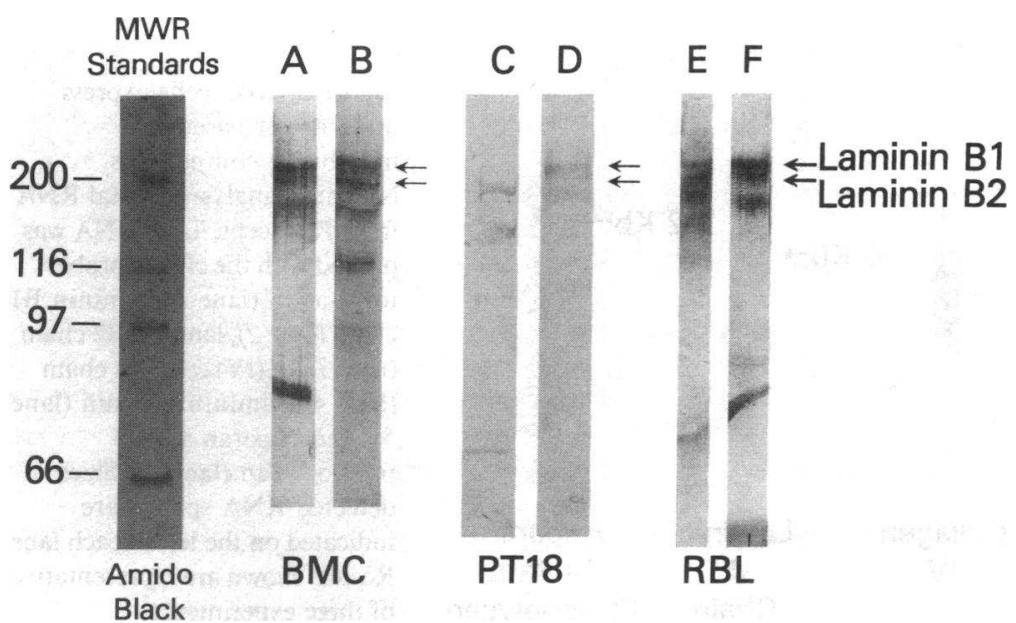

Figure 5. Mast cells synthesize laminin. Immunoblotting of protein from cell pellets $(A, C$, and $E)$ and cell supernatants $(B, D$, and $F)$ from mouse bone marrowderived mast cells $(A, B)$, PT18 cells $(C, D)$, and RBL cells $(E, F)$ with polyclonal antisera to laminin. Results shown are representative of five experiments. Molecular weight standards stained with amido black are shown on the left hand side. 
which mast cells arriving at a specific site when drawn to that site by specific chemotactic factors, could produce a mast cell binding matrix capable of allowing the mast cell to remain at a specific site (38).

\section{Acknowledgments}

We thank Dr. Hynda Kleinman (National Institute of Dental Research) for providing the laminin and collagen IV and I antibodies, and Dr. Robert Hohman (National Institute of Allergy and Infectious Diseases) for providing the RBL cells.

\section{References}

1. Fuller, G. C., and S. W. Mann. 1981. Mechanisms of fibrosis. Rev. Bio chem. Toxicol. 3:193-235.

2. Diegelmann, R. F., and W. J. Lindblad. 1985. Cellular sources of fibrotic collagen. Fundam. Appl. Toxicol. 5:219-227.

3. Ala-Kokko, L., T. Pihlajaniemi, J. C. Meyers, K. I. Kivirkko, and E.-R. Savolainen. 1987. Gene expression of type I, III, and IV collagens in hepatic fibrosis induced by dimethylnitrosamine in the rat. J. Biochem. 244:75-79.

4. Hawkins, R. A., H. N. Claman, R. A. F. Clark, and J. C. Steigerwald. 1985 Increased dermal mast cell populations in progressive systemic sclerosis: a link in chronic fibrosis? Ann. Intern. Med. 102:182-186.

5. Goto, T., D. Befus, R. Low, and J. Bienenstock. 1984. Mast cell heterogeneity and hyperplasia in bleomycin-induced pulmonary fibrosis in rats. Am. Rev. Resp. Dis. 130:797-802.

6. Friedman, B. S., and D. D. Metcalfe. 1989. Mastocytosis. In Biochemistry of the Acute Allergic Reactions. Fifth International Symposium. Alan R. Liss Inc., New York. 163-173.

7. Wichmann, B. E. 1955. The mast cell count during the process of wound healing. Acta. Pathol. Microbiol. Scand. 108(Suppl. 1):5-35.

8. Stracke, M. L., and D. D. Metcalfe. 1986. Glycosaminoglycans and proteoglycans in inflammatory cells. Proc. XII Int. Cong. Allergology Clin. Immunol. 267-289.

9. Ihle, J. N., J. Keller, S. Oroszlan, L. E. Henderson, T. D. Copeland, F. Fitch, M. B. Prystowsky, E. Goldwasser, J. W. Schrader, E. Palaszynski, M. Dy, and B. Lebel. 1983. Demonstration of WEHI-3 growth factor activity, P cell stimulating activity, colony-stimulating activity and histamine-producing cell-stimulating factor activity. J. Immunol. 131:282-287.

10. Razin, E., J. N. Ihle, D. Seldin, J. Mencia-Huerta, H. R. Katz, P. A. Lebalnc, A. Hein, J. P. Caulfield, K. F. Austen, and R. L. Stevens. 1984. Interleukin 3: a differentiation and growth factor for the mouse mast cell that contains chondroitin sulfate E proteoglycan. J. Immunol. 132:1479-1486.

11. Kulczycki Jr., A., C. Isersky, and H. Metzger. 1974. The interaction of IgE with rat basophilic leukemia cells. J. Exp. Med. 139:600-616.

12. Chirgwin, J. M., A. E. Przybyla, R. J. MacDonald, and W. J. Rutter. 1979. Isolation of biologically active ribonucleic acid from sources enriched in ribonuclease. Biochemistry. 18:5294-5299.

13. Lehrach, H., D. Diamond, J. M. Wozney, and H. Boedker. 1977. RNA molecular weight determinations by gel electrophoresis under denaturing conditions, a critical reexamination. Biochemistry. 16:4743-4751.

14. Oberbaumer, I., M. Laurent, U. Schwarz, Y. Sakurai, Y. Yamada, G. Vogeli, T. Voss, B. Siebold, R. Glanville, and K. Kuhn. 1985. Amino acid sequence of the non-collagenous globular domain $\mathrm{NCl}$ of the $\alpha 1$ (IV) chain of basement membrane collagen as derived from complementary cDNA. Eur. J. Biochem. 147:217-224.

15. Sasaki, S., H. K. Kleinman, H. Huber, R. Deutzmann, and Y. Yamada 1988. Laminin-a multidomain protein. The $A$ chain has a unique globular domain and homology with the basement membrane proteoglycan and the laminin B chains. J. Biol. Chem. 263:16536-16544.

16. Sasaki, M., S. Kato, K. Kohno, G. R. Martin, and Y. Yamada. 1987 Sequence of the cDNA encoding the laminin BI chain reveals a multidomain protein containing cystein-rich repeats. Proc. Natl. Acad. Sci. USA. 84:935-939.

17. Sasaki, M., and Y. Yamada. 1987. The laminin B2 chain has a multidomain structure homologous to the B1 chain. J. Biol. Chem. 262:17111-17117.
18. Noonan, D. M., E. A. Horigan, S. L. Ledbetter, G. Vogeli, M. Sasaki, Y. Yamada, and J. R. Hassell. 1988. Identification of cDNA clones encoding different domains of the basement membrane heparan sulfate proteoglycan. J. Biol. Chem. 263:16379-16387.

19. Genovese, C., D. Rowe, and B. Kream. 1984. Construction of DNA sequences complementary to rat $\alpha_{1}$ and $\alpha_{2}$ collagen mRNA and their use in studying regulation of type I collagen synthesis by 1,25 -Dihydroxyvitamin D. Biochemistry. 23:6210-6216.

20. Towbin, H., T. Staehlin, and J. Godron. 1979. Electrophoretic transfer of proteins from polyacrylamide gels to nitrocellulose sheets: procedure and some applications. Proc. Natl. Acad. Sci. USA. 76:4350-4354.

21. Pluznik, D. H., N. S. Tare, M. M. Zatz, and A. L. Goldstein. 1982. A mast cell/basophil cell line dependent on colony stimulating factor. Exp. Hematol. 10:211-216.

22. Sredni, B., M. M. Friedman, C. E. Bland, and D. D. Metcalfe. 1983. Ultrastructural, biochemical and functional characteristics of histamine-containing cells cloned from mouse bone marrow: tentative identification as mucosal mast cells. J. Immunol. 131:915-922.

23. Laurie, G. W., C. P. Leblond, S. Inoue, G. R. Martin, and A. Chung. 1984. Fine structure of the glomerular basement membrane and immunolocalization of five basement membrane components to the lamina densa (basal lamina) and its extensions in both glomeruli and tubules of the rat kidney. Am. J. Anat. 169:463-481.

24. Timpl, R., H. Rohde, P. Gehron Robey, S. I. Rennard, J. M. Foidart, and G. R. Martin. 1979. Laminin: a glycoprotein from basement membranes. J. Biol. Chem. 254:9933-9937.

25. Wicha, S., and T. K. Huard. 1983. Macrophages express cell surface laminin. Exp. Cell Res. 143:475-479.

26. Cornbrooks, C. J., D. J. Carey, J. A. MacDonald, R. Timpl, and R. P. Bunge. 1983. In vivo and in vitro observations on laminin production by Schwann cells. Proc. Natl. Acad. Sci. USA. 80:3850-3854.

27. Kleinman, H. K., I. Ebihara, P. D. Killen, M. Sasaki, F. B. Cannon, Y. Yamada, and G. R. Martin. 1987. Genes for basement membrane components are coordinately expressed in differentiating F9 cells but not in normal adult murine tissues. Dev. Biol. 122:373-378.

28. Hahn, E., G. Wick, D. Pencev, and R. Timpl. 1980. Distribution of basement membrane proteins in normal and fibrotic human liver: collagen type IV laminin and fibronectin. Gut. 21:63-71.

29. Carlsson, R., E. Engvall, A. Freeman, and E. Ruoslahti. 1981. Laminin and fibronectin in cell adhesion: enhanced adhesion of cells from regenerating liver to laminin. Proc. Natl. Acad. Sci. USA. 78:2403-2406.

30. Madri, J. A., and H. Furthmayer. 1980. Collagen polymorphism in the lung - an immunochemical study of pulmonary fibrosis. Hum. Pathol. 11:353366.

31. Couchman, J. R., M. Hook, D. A. Rees, and R. Timpl. 1983. Adhesion, growth and matrix production by fibroblasts on laminin substrates. J. Cell Biol. 96:177-183.

32. Roberts, R., J. Gallagher, E. Spooncer, T. D. Allen, F. Bloomfield, and T. M. Dexter. 1988. Heparan sulfate bound growth factors: a mechanism for stromal cell mediated haemopoiesis. Nature (Lond.). 332:376-378.

33. Plaut, M., J. H. Pierce, C. J. Watson, J. Hanley-Hyde, R. P. Nordan, and W. E. Paul. 1989. Mast cell lines produce lymphokines in response to crosslinkage of $\mathrm{Fc}_{\mathrm{E}} \mathrm{RI}$ or to calcium ionophores. Nature (Lond.). 339:64-67.

34. Burd, P. R., H. W. Rogers, J. R. Gordon, C. A. Martin, S. Jayaraman, S. D. Wilson, A. M. Dvorak, S. J. Galli, and M. E. Dorf. 1989. Interleukin-3-dependent and independent mast cells stimulated with IgE and antigen express multiple cytokines. J. Exp. Med. 170:245-257.

35. Bussolino, F., J. Ming Wang, P. Defilippi, F. Turrini, F. Sanavio, C.-J. S. Edgell, M. Anglietti, P. Arese, and A. Mantovani. 1989. Granulocyte and granulocyte-macrophage colony stimulating factors induce human endothelial cells to migrate and proliferate. Nature (Lond.). 337:471-473.

36. Thompson, H. L., P. D. Burbelo, B. Segui-Real, Y. Yamada, and D. D. Metcalfe. 1989. Laminin promotes mast cell attachment. J. Immunol. 143:23232328.

37. Thompson, H. L., P. D. Burbelo, D. D. Metcalfe, and Y. Yamada. 1990. Laminin induces mast cell gene expression and alters their nuclear transcription factors. FASEB (Fed. Am. Soc. Exp. Biol.) J. 4:A1944. (Abstr.)

38. Terranova, V. P., R. Diflorio, E. S. Hujanen, R. M. Lyall, L. A. Liotta, U. Thorgeirsson, G. P. Siegal, and E. Schiffman. 1986. Laminin promotes rabbit neutrophil motility and attachment. J. Clin. Invest. 77:1180-1186. 